CDD: 001.644

\title{
OS BENEFÍCIOS DAS TECNOLOGIAS DA INFORMAÇÃO E COMUNICAÇÃ̃O (TIC) NO PROCESSO DE EDUCAÇÃO A DISTÂNCIA (EAD)
}

Resumo: Este artigo apresenta, com base na literatura pesquisada acerca do tema, o conceito, as características e os benefícios proporcionados pelo uso das Tecnologias de Informação e Comunicação (TIC) na Educação a Distância (EAD), de maneira a facilitar o processo ensinoaprendizagem, assim como incentivar a disseminação de informações e experiências entre alunos e professores e/ou tutores. Também mostra exemplos de ferramentas tecnológicas utilizadas na EAD com o intuito de favorecer tal comunicação.

Palavras-chave: Tecnologia de Informação e Comunicação - TIC. Educação a Distância EAD. Inovação Tecnológica.

Abstract: This paper presents, based on the literature review, the concept, the features and the benefits provided by the use of Information Technologies and Communication (TIC) in Distance Education, in order to facilitate the teaching-learning process, as well as encourage the dissemination of information and experiences between students and teachers and/or tutors. It also presents examples of technological tools used by EAD to facilitate such communication.

Key-words: Information and Communication Technologies - TIC. Distance Education - DL. Technological Innovation.

\footnotetext{
${ }^{1}$ Bibliotecária formada pela Universidade Federal do Rio Grande (FURG), Rio Grande/RS. Brasil. Email: suelen.c.farias@gmail.com
} 


\section{INTRODUÇÃO}

Nos dias atuais, vive-se um período caracterizado pelas transformações que acompanham as tecnologias de informação e comunicação (TIC), bem como a inserção na chamada Sociedade da Informação. Tal Sociedade relaciona-se com as inovações tecnológicas, as quais são responsáveis pela velocidade com que informações são produzidas e disseminadas, bem como pelo ritmo intenso do cotidiano da população. Em razão disso, é comum, cada vez menos, dispor de tempo hábil para frequentar um curso de maneira totalmente presencial; nesse sentido, alternativas como a Educação a Distância (EAD), contribuem para a formação de profissionais capazes de trabalhar, positivamente, com a contínua e acelerada transformação das ferramentas tecnológicas.

O presente artigo destina-se a apresentar, com base na literatura acerca do tema, os benefícios proporcionados pelo uso das TIC na educação a distância, de modo a facilitar o processo ensino-aprendizagem, bem como favorecer, por meio de Ambientes Virtuais de Aprendizagem (AVA), a troca de informações e experiências entre alunos e professores e/ou tutores. Tais profissionais têm a possibilidade de desenvolver debates, fóruns, trabalhos em grupo, dentre outras alternativas, de maneira a incentivar o uso das TIC, tornando a aprendizagem mais significativa.

Segundo Moran (2010 p. 03),

\footnotetext{
“o futuro será aprender em qualquer tempo e lugar, de forma personalizada e, ao mesmo tempo, colaborativa e com flexibilidade curricular, no quadro de um novo conceito de "estarmos juntos", conectados virtualmente".
}

\section{O QUE SIGNIFICA A EDUCAÇÃO A DISTÂNCIA?}

A educação a distância (EAD) é um sistema de aprendizagem com ênfase no aluno, permitindo que o mesmo tenha acesso às fontes de ensino, por meio de dispositivos eletrônicos e multimídia, os quais fornecem uma independência em termos de tempo e/ou espaço, assim como uma maior interação entre os alunos com o professor e/ou tutor, utilizando tais dispositivos.

Com base na definição acima, observa-se que a EAD propicia a criação de um novo ambiente educacional, em que o aluno precisa ser um indivíduo capaz de 
mostrar autonomia e comprometimento com a aquisição de conhecimento, estimulando, dessa forma, o processo ensino-aprendizagem. Nesse método de ensino, o professor é visto como um colaborador, o qual contribui com a educação do aluno, compartilhando informações por meio de ferramentas tecnológicas.

De acordo com Pelissoli e Loyolla (2004 p. 02):

A independência de tempo e lugar favorece a aprendizagem, pois a atual necessidade de locomoção dos profissionais e a crescente necessidade de sua capacitação tornam importante a criação de mecanismos que possibilitem ao estudante continuar a aprender mesmo estando fora da instituição de ensino.

O uso de métodos de aprendizagem de forma não presencial, por meio de materiais impressos, os quais possibilitaram aos indivíduos a autoaprendizagem, tem na imprensa de Gutenberg, inventada em 1453, as condições necessárias para o seu aparecimento, ganhando expressão com a Revolução Industrial, no século XIX. Com isso, surge a primeira geração da $\mathrm{EAD}$, em que livros, manuais, troca de correspondências pelos Correios, além de outros materiais, eram usados como recursos principais. (RAMÍSIO, 2010).

Já a segunda geração da EAD iniciou com a evolução dos meios de informação e comunicação, cujos destaques, na época, eram o rádio e a televisão. Com a integração desses recursos aos materiais impressos, o processo de comunicação passou a ter como característica o fato de ser expositivo, síncrono e unidirecional $^{2}$ como, por exemplo, a "tele-escola". (RAMíSIO, 2010).

Hoje, vive-se a terceira geração da educação a distância, a qual ocorre com o surgimento das novas tecnologias informacionais e de comunicação; tecnologias essas que recebem maior importância em razão da necessidade de expandir os níveis de educação e de formação, tanto inicial como contínua. As TIC representam, ainda, um avanço na EAD, já que, a partir da criação de ambientes virtuais, os estudantes podem se relacionar, bem como disseminar informações e compartilhar experiências, favorecendo, assim, o processo de aprendizagem.

De acordo com Brasil (2000):

${ }^{2} \mathrm{O}$ que possui somente uma direção; objetivo único. 
Educar, em uma Sociedade da Informação, significa muito mais que treinar pessoas para o uso das tecnologias de informação e comunicação: trata-se de investir na criação de competências amplas que permitam uma atuação efetiva na produção de bens serviços, na tomada de decisões fundamentadas no conhecimento, na operação de novos meios e ferramentas em seu trabalho, bem como na aplicação das novas mídias. [...] Trata-se também de formar os indivíduos para "aprender a aprender", de modo a serem capazes de lidar positivamente com a acelerada transformação da base tecnológica.

Igualmente, para Tarouco, Moro e Estabel (2003 p. 03)

Educar a distância significa saber utilizar as ferramentas das tecnologias de informação e comunicação, não só disponibilizando materiais, mas interagindo, aprendendo em grupos, cooperando, colaborando e transformando.

Entre as vantagens que a EAD oferece, pode-se considerar:

- A possibilidade de desenvolver uma melhor gestão do tempo, de acordo com a disponibilidade do educando;

- A facilidade na atualização, no acesso e no compartilhamento de informações, independentemente das distâncias geográficas;

- As diversas formas de interação, bem como trocas de experiências entre os alunos e o professor e/ou tutor.

Ademais, a adaptação a esse novo método de ensino faz com que o professor/tutor passe a ser considerado um mediador da aprendizagem, tornando-se necessário o domínio das ferramentas informacionais, além da capacidade de formar alunos críticos, participativos e, sobretudo, autônomos no processo ensinoaprendizagem. Contudo, para que isso ocorra, o profissional da EAD deve apresentar competências, a fim de desenvolver ambientes atrativos e que satisfaçam às necessidades e aos interesses dos educandos, bem como incentivar o uso de diferentes ferramentas de comunicação, como: chat, fórum de discussão, correio eletrônico $(e$ mail), videoconferência, blog, entre outros, os quais serão exemplificados posteriormente. 
Tais recursos são utilizados na geração atual da EAD, de modo a tornar o seu processo mais eficaz, assim como reduzir os obstáculos referentes às distâncias geográficas, locais e horários das aulas. Igualmente, os recursos devem ser selecionados conforme os objetivos pedagógicos do curso, proporcionando um ambiente motivador, o qual favoreça o aluno na construção da autoaprendizagem.

Para Coutinho e Bottentuit Júnior (2007 a p. 01):

\begin{abstract}
A cada dia mais pessoas estudam em casa, podendo, de lá, aceder ao ciberespaço da formação e da aprendizagem a distância, buscar fora da escola a informação disponível nas redes de computadores e em serviços disponibilizados pela internet, que respondem as suas exigências pessoais de conhecimento.
\end{abstract}

Já no que se refere às modalidades de comunicação na educação a distância, essas podem ser classificadas conforme sua natureza de comunicação entre professores/tutores e alunos, como:

\title{
2.1 CURSO DE NATUREZA SÍNCRONA
}

O curso realizado via comunicação síncrona, ou direta, exige que os interlocutores estejam conectados ao serviço simultaneamente, a fim de que mensagens sejam trocadas entre eles. É considerado um tipo de comunicação interativa, sendo muito empregada nos cursos de EAD. Como exemplos, citam-se telefone, chat, videoconferência, entre outros.

Em se tratando dos seus benefícios, observa-se:

- Maior interação com o professor/tutor: os alunos podem interagir com mais facilidade, por meio dos mecanismos de comunicação síncrona, já que suas dúvidas podem ser respondidas por chat, durante conversa com o professor, ou em alguns casos, o tutor online esclarece determinadas questões até mesmo por telefone;

- Melhor feedback: sistemas síncronos favorecem um retorno mais rápido aos educandos, visto que, em geral, a comunicação entre os mesmos e seus professores/tutores ocorre instantaneamente;

- Motivação: os mecanismos de origem síncrona enfatizam uma maior sinergia de grupo, motivando o aluno a prosseguir o curso. 
Todavia, os métodos de comunicação síncrona podem apresentar, como desvantagem, alto curso de infraestrutura, na medida em que exigem, para seu funcionamento, equipamentos mais sofisticados. Ainda, de acordo com Silva et al. [s.d.] "implica uma enorme logística para preparar os meios de comunicação e precisa ser agendado, perdendo a flexibilidade de horários".

Em razão disso, instituições de $\mathrm{EAD}$, em sua maioria, utilizam tanto ferramentas de comunicação síncrona como assíncrona, com o propósito de melhorar os custos e oferecer maior flexibilidade ao aluno.

\subsection{CURSO DE NATUREZA ASSÍNCRONA}

Este curso caracteriza-se pelo tipo de comunicação, o qual possui momentos para envio e recebimento de mensagens, podendo ser realizado em tempos distintos. Com isso, a interação torna-se mais flexível, já que há a possibilidade de o aluno encaminhar suas dúvidas a qualquer momento e o professor/tutor respondê-las sem a preocupação da iminência do final da aula. Entre os exemplos de comunicação assíncrona, ou indireta, estão: correio eletrônico, fórum de discussão, páginas Web e lista de discussão.

Com relação às vantagens de tal modelo, pode-se considerar:

- Maior flexibilidade de horário e lugar: o estudante pode dedicar-se ao aprendizado do conteúdo no período e no local em que lhe for mais apropriado, sem necessidade de estar conectado no mesmo instante que os demais colegas e/ou professores;

- Tempo para reflexão: instrutores e alunos possuem maior tempo para o esclarecimento de dúvidas a respeito do conteúdo, com a possibilidade de consulta a outras fontes, de modo a aprimorar o conhecimento;

- Custo razoável: mecanismos de comunicação assíncrona exigem menor sofisticação, no que se refere às tecnologias, baseando-se, em geral, em textos, slides, facilitando, assim, o oferecimento de cursos, acesso e redução de custos.

Entretanto, os recursos de natureza indireta podem causar, como desvantagem, o isolamento, pois a interação do participante com seus colegas e/ou professores não ocorre em tempo real, fato esse que pode fazer com que o aluno sinta-se isolado e desmotivado (SILVA et al. [s.d.]) 
Para que os meios de comunicação síncrona e assíncrona possam ser utilizados na EAD, faz-se necessário o desenvolvimento do Ambiente Virtual de Aprendizagem (AVA), definido como uma construção amigável e acessível, a qual visa à interação do aluno, em uma perspectiva em que o mesmo não se encontra presencialmente com o professor; portanto, cabe a esse profissional elaborar conteúdos adaptados ao novo método de ensino. É também um processo em constante construção e que diminui, de maneira significativa, as distâncias tão mencionadas na educação.

Outrossim, segundo pesquisa desenvolvida pelo Anuário Brasileiro Estatístico de Educação Aberta e a Distância (AbraEAD) e publicada em 2008, 01 em cada 73 brasileiros estuda pelo método EAD, sendo que, no ano de 2007, mais de 2,5 milhões de brasileiros estudaram em cursos com metodologias a distância. A pesquisa incluiu não somente cursos de instituições credenciadas pelo Sistema de Ensino, mas também projetos como os da Fundação Bradesco, Fundação Roberto Marinho e os do Grupo S (Sesi, Senac, Senai, Sebrae, etc). Já de acordo com reportagem no jornal Zero Hora (2012), em 2001, o Brasil registrou 5.359 matrículas em tal modalidade, sendo que, no último censo do Ministério da Educação e Cultura (MEC), no ano de 2010, esse número cresceu para 930.179 matrículas.

\section{AS TECNOLOGIAS DE INFORMAÇÃO E COMUNICAÇÃO}

Tecnologia de Informação e Comunicação (TIC) pode ser considerada como um conjunto de recursos tecnológicos, os quais permitem maior facilidade no acesso e na disseminação de informações. Tais tecnologias encontram-se presentes no dia a dia da Sociedade Contemporânea, nas mais distintas formas, sendo que, uma das áreas mais favorecidas com o uso das TIC é a educacional.

Segundo Lévy (1998 p. 24):

Poucas inovações tecnológicas provocaram tantas mudanças em tão pouco tempo na sociedade como as novas tecnologias de informação e comunicação - TIC. Dentro dessas mudanças está incluída a educação. Novas maneiras de pensar e conviver estão sendo elaboradas no mundo das telecomunicações e da informática. 
O uso de ferramentas tecnológicas no processo ensino-aprendizagem é importante para fomentar os recursos didáticos, auxiliar na inclusão digital, além de possibilitar o compartilhamento de informações e experiências entre os educandos. Castells (2000 p. 57) considera que "as novas tecnologias de informação estão integrando o mundo em redes globais de instrumentalidade. A comunicação mediada por computadores gera uma gama de comunidades virtuais".

A seguir, alguns exemplos de recursos tecnológicos, os quais são utilizados no método EAD, com o propósito de facilitar os processos de comunicação e interação.

\subsection{CHAT}

O chat, cujo significado em português é conversação ou bate-papo, é uma ferramenta síncrona que possibilita, por meio da internet, a conversação simultânea entre os usuários. Isso ocorre em ambientes remotos, através de mensagens escritas, que podem ser visualizadas em grupo ou de maneira particular e reservada, pelos participantes. No que se refere à EAD, o chat permite que os estudantes compartilhem ideias, esclareçam dúvidas acerca do conteúdo programático, dentre outros procedimentos.

Todavia, tal recurso pode provocar desmotivação e/ou desvio do objetivo pretendido, visto que o mecanismo não possui controle a respeito do que será discutido; em razão disso, alguns alunos podem perder o estímulo em fazer parte da discussão, bem como desviar o foco do assunto em debate (BRITO [s.d.]) Sendo assim, é fundamental o papel do professor/tutor para que haja um melhor aproveitamento dessa ferramenta. Ele deve identificar a frequência com que os alunos estão participando, de modo a incentivar a utilização, propondo questões que motivem o compartilhamento de opiniões.

Ademais, outro fator importante é o armazenamento das conversações realizadas, proporcionando ao aluno que não participou do chat a possibilidade de o mesmo ter ciência do que foi discutido, ou ainda que algum membro do grupo examine mais detalhadamente a discussão realizada. 


\subsection{FÓRUM DE DISCUSSÃO}

Este dispositivo virtual de natureza assíncrona destina-se a promover debates entre os participantes, a partir de mensagens publicadas na página, as quais abordam um determinado assunto. Também é possível incluir sugestões, reflexões e ideias, a fim de proporcionar a troca de experiências e saberes.

Um fórum pode ser classificado conforme o assunto e as mensagens relacionadas ao mesmo, organizando-as de forma hierárquica, o que permite a identificar a sequência dos debates e o assunto a que estão relacionadas (FISCHER, 2000).

Com relação ao seu uso na educação a distância, pode-se considerar o fórum como um importante instrumento de diálogo, já que oferece um espaço de aprendizagem individual e coletiva, em que todos os participantes têm a oportunidade de contribuírem com suas opiniões acerca do tema em questão.

Tal recurso possui uma interface rica, capaz de potencializar a comunicação e o compartilhamento de ideias. Ele é amplamente utilizado em cursos na modalidade a distância, com o objetivo de promover a interação entre grupos de alunos e professores. (SILVA, 2006).

\subsection{BLOG}

Weblog, popularmente conhecido como blog, é definido como uma página interativa que, por meio da internet, permite publicações de artigos, notícias, ilustrações, entre outros, cujo principal objetivo é oferecer aos leitores e escritores o compartilhamento de experiências e saberes, por meio da interação entre os participantes. Tais publicações, chamadas de post, são organizadas cronologicamente, sendo que a postagem mais recente sempre recebe maior destaque, ao ser exibida no topo da página.

Uma característica importante do blog, o qual é considerado um meio de comunicação assíncrono, é a possibilidade que os participantes têm de comentar as postagens, estimulando, com isso, a interação entre o escritor e seu público. Esse recurso define o blog como uma considerável mídia social, a qual promove a formação de grupos de usuários que compartilham interesses em comum. 
No que diz respeito ao seu uso em cursos EAD, observa-se que o processo ensino-aprendizagem, por meio de tal método, possibilita o diálogo entre os participantes, bem como o trabalho colaborativo, incentivando a disseminação de informações que, ao serem publicadas, analisadas e compartilhadas, poderão desenvolver a autonomia desses participantes.

Outrossim, o blog oferece inúmeras opções de atividades, tanto ao aluno como ao professor/tutor, tornando-se possível o intercâmbio entre instituições educacionais, com a finalidade de debater assuntos, opiniões, ideias, favorecendo, assim, a produção escrita e a leitura, além de auxiliar na formação de alunos capazes de aprimorar seus conhecimentos.

Entre os objetivos da utilização dessa ferramenta na educação a distância, considera-se: construção do conhecimento de forma colaborativa; incentivo à comunicação por meio da escrita e da leitura; e, desenvolvimento da habilidade de interação entre os participantes (GONÇALVES, 2007).

\subsection{CORREIO ELETRÔNICO}

Correio eletrônico, mais conhecido como e-mail, é considerado um dos serviços mais utilizados na internet, visto que o mesmo possibilita o envio de arquivos anexados em diversos formatos, como, por exemplo, texto, imagem, áudio e vídeo, para qualquer pessoa e/ou organização.

O e-mail provocou grande impacto nas relações de comunicação, reduzindo os custos e aumentando a velocidade na disseminação de informações. Assim, o uso dessa ferramenta assíncrona tornou-se comum nos mais diferentes campos e com propósitos variados, podendo ser utilizada para o envio de uma simples mensagem ao amigo, como para o envio de documentos importantes.

Além disso, no processo de EAD, o e-mail exerce papel fundamental, já que o mesmo contribui para a interação entre alunos e professores/tutores, englobando, de um modo geral, todos os envolvidos com o curso e/ou com a administração do ambiente virtual, tornando-se possível fazer questionamentos, comentários e sugestões. Contudo, sua utilização deve ser exercida com cuidado, já que pode causar desmotivação no aluno, caso não sejam observados certos aspectos, como: tempo de 
resposta; sobrecarga do professor; sistematização de questões; e, sistematização de respostas (ROMANI; ROCHA, 2001).

Com tal ferramenta, é possível organizar um curso de EAD completo, desde a inscrição dos alunos até o recebimento de atividades e disponibilização de conteúdos, bem como:

- Elaboração de textos: o professor pode acompanhar a elaboração de um texto, por meio do correio eletrônico, auxiliando o aluno durante o processo. Todas as versões anteriores do texto, com as correções indicadas, permanecem armazenadas, podendo ser utilizadas como histórico;

- Envio de textos ou outros materiais: o professor também pode encaminhar, por e-mail, à turma um texto para leitura ou análise. Com base nesse texto, há a possibilidade de ser desenvolvida uma discussão acerca do mesmo, utilizando-se, para isso, uma ferramenta direta como o chat ou o fórum de discussão, a fim de estimular a interatividade entre os educandos;

- Canal de comunicação: alunos e professores e/ou tutores e podem usar esse recurso, de forma individualizada ou em grupo, para marcar reuniões, esclarecer dúvidas, trocar informações, entre outras atividades;

- Desenvolvimento de uma lista de discussão para a turma.

\subsection{VIDEOCONFERÊNCIA}

A videoconferência, considerada um método de comunicação síncrona, possibilita, entre os participantes, a conversa em duas vias, permitindo, na EAD, que o processo ensino-aprendizagem ocorra em tempo real (online), já que as pessoas podem se vir e ouvir simultaneamente. Devido às ferramentas didáticas disponíveis nesse ambiente, o professor, na medida em que explica um determinado conceito, pode acrescentar outros recursos pedagógicos, como gráficos, projeção de vídeos, imagens, slides, arquivos de computador, entre outros (CRUZ; BARCIA, 2000).

Tal sistema permite ainda que o aluno, durante a apresentação, esclareça suas dúvidas, interagindo com o professor. Assim, pode-se constatar que a videoconferência é uma tecnologia que proporciona a grupos distantes geograficamente a comunicação por meio de sinais de áudio e vídeo. Essa transmissão pode acontecer tanto por satélite como por linhas telefônicas. 
Cyrs e Conway (1997) mencionam algumas competências que o professor/tutor precisa desenvolver, a fim de fazer uso da videoconferência em suas aulas:

- Planejamento e organização do material didático;

- Habilidade de apresentação verbal e não verbal;

- Capacidade de incentivar o trabalho em grupo e motivar o aluno a interagir durante as aulas;

- Domínio de estratégias de questionamento;

- Capacidade de desenvolver um raciocínio gráfico e pensar visualmente.

No que diz respeito às vantagens que esse recurso pode oferecer, considera-se, segundo Cruz e Moraes (1997), que:

- Proporciona uma transição mais gradual dos métodos presenciais de ensino;

- Possibilita escolher e planejar aulas mais interativas para turmas pequenas, ou menos interativas para grandes audiências;

- Permite optar pelos meios de transmissão, conforme a possibilidade, a disponibilidade e a demanda.

Todavia, como as demais ferramentas tecnológicas, a videoconferência apresenta limitações, como, por exemplo:

- Possibilidade de ocorrer baixa qualidade de som e imagem;

- Altos custos de implementação, instalação e manutenção, bem como de transmissão via linha telefônica;

- Desconhecimento de todo o potencial didático que esse recurso oferece, reduzindo-o, assim, a mera reprodução de palestras, com pouca interação entre os participantes.

\section{CONSIDERAÇÕES FINAIS}

Diante do que foi apresentado no artigo, identifica-se que o método EAD vem conquistando mais espaço a cada dia, na medida em que propicia ao aluno facilidade no acesso às fontes de ensino, além da rapidez dos seus feedbacks às questões propostas.

Igualmente, com as ferramentas tecnológicas provenientes das TIC, a interação entre os estudantes e seus professores/tutores torna-se maior, bem como o 
compartilhamento de informações e experiências entre os mesmos, contribuindo, assim, para a eficácia do processo ensino-aprendizagem.

No entanto, para que todos os recursos possam ser bem utilizados, é necessário que o professor e/ou tutor domine tais ferramentas, de modo a proporcionar motivação nos alunos quanto ao uso das mesmas. Também é importante que esses profissionais sejam capazes de formar alunos críticos e participativos, desenvolvendo, para isso, ambientes atrativos que atendam aos interesses dos usuários. 


\title{
REFERÊNCIAS
}

\begin{abstract}
ANUÁRIO BRASILEIRO ESTATÍSTICO DE EDUCAÇÃO ABERTA E A DISTÂNCIA (AbraEAD). Disponível em: < http://www.abraead.com.br/noticias.cod=x1.asp > . Acesso em: 18 set. 2012.
\end{abstract}

BRASIL. Ministério da Ciência e Tecnologia. Sociedade da Informação no Brasil: livro verde. Brasília, 2000.

BRITO, M. S. S. Tecnologias para a EAD via internet. [19--?]. Disponível em: <http://www.lynn.pro.br/pdf/educatec/brito.pdf >. Acesso em: 12 set. 2012.

CASTELLS, M. A sociedade em rede. 11. ed. São Paulo: Paz e Terra, 2000.

COUTINHO, C. P.; BOTTENTUIT JÚNIOR, J. B. A complexidade dos modos de aprender na Sociedade do Conhecimento. Lisboa: [s.n.], 2007a.

CYRS, T. E.; CONWAY, E. D. Teaching at a distance with the mergin technologis: an instructional systems approach. Las Cruces: New Mexico State University, 1997.

CRUZ, D. M.; BARCIA, R. M. Educação a distância por videoconferência. Tecnologia Educacional, ano 28, n. 150/151, jul./dez. 2000.

CRUZ, D. M; MORAES, M. Manual de videoconferência. Florianópolis: Ed. da UFSC, 1997.

FISCHER, G. S. Um ambiente virtual multimídia de ensino na web com transmissão ao vivo e interatividade. 2000. Dissertação (Mestrado em Informática) - Universidade Federal do Rio Grande do Sul, Porto Alegre, 2000.

GONÇALVES, H. P. Blog: uma ferramenta do ensino a distância. Disponível em: 〈http://www.slideshare.net/hildapinto/blog-uma-ferramenta-do-ead>. Acesso em: 22 set. 2012.

LÉVY, P. As tecnologias da inteligência: o futuro do pensamento da era da informática. 34. ed. 1998.

MORAN, J. M. A distância e o presencial cada vez mais próximos. Disponível em: <http://www.eca.usp.br/moran/proximos.htm>. Acesso em: 18 jul. 2013.

PELISSOLI, L.; LOYOLLA, W. Aprendizado Móvel (M-LEARNING): dispositivos e cenários. Disponível em: 〈http://www.abed.org.br/congresso2004/por/htm/074-TC-C2.htm〉. Acesso em: 22 set. 2012.

RAMÍSIO, A. O b-learning no contexto da educação a distância. Disponível em: <http://www.slideshare.net/arturramisio/artigo-blearning-apr>. Acesso em: 14 set. 2012.

ROMANI, L. A. S.; ROCHA, H. V. A complexa tarefa de educar a distância: uma reflexão sobre o processe educacional baseado na web. Revista Brasileira de Informática na Educação, Florianópolis, n.8, p. 71-81, 2001.

SILVA, L. et al. Formas de comunicação no EAD: estratégias síncronas e assíncronas. [19-?]. Disponível em: <http://www.slideshare.net/Sufea/formas-de-comunicao-no-ead-estratgiassncronas-e-assncronas $>$. Acesso em: 18 jul. 2013.

SILVA, M. Criar e professorar um curso online: relato de experiência. Educação online. 2. ed. São Paulo: Loyola, 2006.

TAROUCO, L. M. R.; MORO, E. L. S.; ESTABEL, L. B. O professor e os alunos como protagonistas na educação aberta e a distância mediada por computador. In: Educar, 2003. 
Disponível em: <http://ojs.c3sl.ufpr.br/ojs2/index.php/educar/article/view/2121/1773 > Acesso em: 18 set. 2012.

ZERO HORA. Procura por EAD cresce no Brasil. Disponível em: <http://zerohora.clicrbs.com.br/rs/geral/vestibular/noticia/2012/06/procura-por-ead-cresce-nobrasil-3795492.html>. Acesso em: 18 set. 2012.

\section{Como citar este artigo:}

FARIAS, Suelen Conceição. Os benefícios das tecnologias de informação e comunicação (TIC) no processo de educação a distância (EAD). Rev. digit. bibliotecon. cienc. inf., Campinas, SP, v.11, n.3, p.15-29, ago/nov. 2013. ISSN 1678-765X.

Disponível em: <http://www.sbu.unicamp.br/seer/ojs/index.php/rbci> 